\title{
Analysis of phase coherence in fully developed atmospheric turbulence: Amazon forest canopy
}

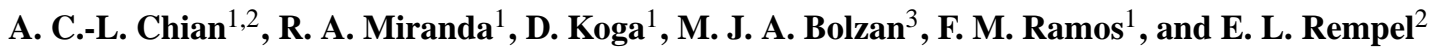 \\ ${ }^{1}$ National Institute for Space Research (INPE) and World Institute for Space Environment Research (WISER), P. O. Box 515, \\ São José dos Campos-SP 12227-010, Brazil \\ ${ }^{2}$ Institute of Aeronautical Technology (ITA), CTA/ITA/IEFM, São José dos Campos-SP 12228-900, Brazil \\ ${ }^{3}$ Instituto de Pesquisa e Desenvolvimento, Universidade do Vale do Paraíba (UNIVAP), São José dos Campos-SP \\ 12224-000, Brazil
}

Received: 17 March 2008 - Revised: 12 June 2008 - Accepted: 12 June 2008 - Published: 23 July 2008

\begin{abstract}
In a recent paper (Koga et al., 2007) it was shown that the intermittent nature of solar wind turbulence can be characterized by kurtosis and phase coherence index. In this paper, we apply these two nonlinear time series techniques to characterize the intermittent nature of atmospheric turbulence above and within the Amazon forest canopy using the day-time data of temperature and vertical wind velocity measured by a micrometeorological tower at two different heights. By applying kurtosis and phase coherence index to quantify the degree of phase coherence, we identify an enhanced scalar-velocity similarity for in-canopy turbulence compared to the above-canopy turbulence, during the interval of data analysis.
\end{abstract}

\section{Introduction}

Amazon rain forest plays a key role in the regional and global climate dynamics. One important problem for understanding the vegetation-atmosphere interactions in Amazonia is the turbulent exchange of scalar and momentum in the atmospheric boundary layer - above and within the forest canopy.

Atmospheric turbulence in the Amazon forest has been investigated extensively. For example, Fitzjarrald et al. (1990) performed detailed observations of turbulence just above and below the crown of an Amazon forest during the wet season. This analysis shows that the forest canopy removes high-frequency turbulent fluctuations while passing lower frequencies. A study of $\mathrm{CO}_{2}$ concentration was made

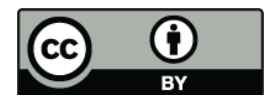

Correspondence to: A. C.-L. Chian (achian@dge.inpe.br) by Sternberg et al. (1997) in two different forests in the Amazon basin during the dry season, one site characterized by a closed canopy structure in which turbulent mixing is minimized and another site characterized by an open canopy structure in which the turbulent mixing is maximized. This analysis shows that the respiratory $\mathrm{CO}_{2}$ recycling in the closed canopy forest with lower wind speeds is occurring to a greater extent than the open canopy forest with higher wind speeds. The vertical dispersion of trace gases using a Lagrangian approach was analyzed by $\mathrm{Si}$ mon et al. (2005) based on in-canopy turbulence data collected at Jaru and Cuieiras Reserves. This study indicates that for day-time conditions when there is an efficient turbulent mixing in the upper canopy and profile gradients are small, the radon-222 source/sink distributions show a high sensitivity to small measurement errors and the $\mathrm{CO}_{2}$ and $\mathrm{H}_{2} \mathrm{O}$ fluxes show a reasonable agreement with the eddy covariance measurements made above the forest canopy, which is not the case for night-time conditions when the $\mathrm{CO}_{2}$ profile gradients in the upper canopy are large due to reduced turbulent mixing.

The intermittent characteristics of atmospheric turbulence above and within a forest canopy has been discussed by a number of papers. For example, a review of turbulence in plant canopies was written by Finnigan (2000) who noted an upsurge of interest in canopy turbulence sparked by the need to understand global biochemical cycles and their role in climate change. An analysis of fine-scale canopy turbulence in an Amazon forest based on the generalized Tsallis' thermostatistics theory was performed by Bolzan et al. (2002). This investigation shows that the entropy parameter $q$ from Tsallis' non-extensive statistics, that controls the shape of the probability density function (PDF) of velocity

Published by Copernicus Publications on behalf of the European Geosciences Union and the American Geophysical Union. 

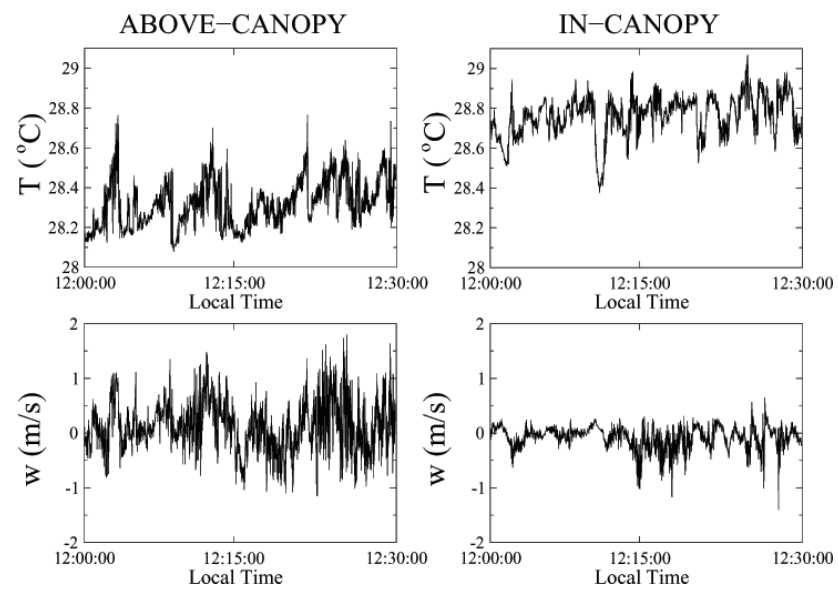

Fig. 1. Time series of temperature $T$ and vertical wind velocity $w$ above the Amazon forest canopy (left panels) and within the Amazon canopy (right panels), taken from noon to 12:30 on Julian Day 068, 1999.

and temperature differences, can be used to quantify the intermittency buildup in atmospheric turbulent flows. Ramos et al. (2004) extended the study of Bolzan et al. (2002) to investigate how the entropy parameter $q$ varies from above to within the forest canopy, or when the atmosphere changes from day/unstable to night/stable conditions. In addition, it is shown that large-scale, ramp-like, coherent structures in the temperature fields affect the properties of the inertial subrange resulting in an increase of the temperature kurtosis above the canopy. Using time series of turbulent velocity and scalar concentration collected in the atmosphere above a temperate pine forest, Katul et al. (2006) demonstrated that Tsallis' non-extensive thermostatistics provides a unifying framework to study two inter-connected problems: dissimilarity between scalars and velocity statistics within the inertial subrange and contamination of internal intermittency by external factors. This work indicates that the dissimilarity in statistics between velocity and scalars within the inertial subrange is strongly dependent on external intermittency. Thomas et al. (2006) applied a Doppler-Sodar to observe coherent structures in the roughness sublayer above forest canopy, and found that the turbulent flow is a superposition of dynamic Kelvin-Helmholtz instabilities and convective mixing.

In analytic modeling and numerical simulations of intermittent turbulence based on a set of deterministic equations, in the absence of noise, it is naturally expected that the departure from Gaussianity is due to phase coherence related to nonlinear interactions (Frisch, 1995). In contrast, the observational data of atmospheric turbulence is an admixture of deterministic signal and stochastic noise. In such case, a demonstration of finite phase coherence is required to ascertain the nonlinear origin of non-Gaussian fluctuations. Recently, a phase coherence technique based on surrogate data has been developed for nonlinear space data analysis (Hada et al., 2003; Nariyuki and Hada, 2006; Koga et al., 2008). The link between phase coherence, non-Gaussianity and intermittent turbulence was established by Koga et al. (2007), based on GEOTAIL magnetic field data upstream and downstream of the Earth's bow shock. The aim of this paper is to apply the kurtosis (fourth-order structure function) and phase coherence techniques to determine the intermittent nature of day-time atmospheric turbulence above and within the Amazon forest canopy. In particular, we show that both techniques are capable of characterizing the dissimilarity of scalar and velocity in above-canopy and in-canopy atmospheric turbulence.

\section{Amazon forest canopy data}

A major atmospheric mesoscale campaign during the wet season of the Large-Scale Biosphere-Atmosphere Experiment in Amazonia (LBA) was carried out in January-March 1999 (Silva Dias et al., 2002). LBA is an international project led by Brazil designed to study: 1) the climatological, ecological, biogeochemical, and hydrological functions of the Amazon region, 2) the impact of land uses caused by deforestation, and 3) the interactions between Amazonia and the Earth system. As part of this campaign, a micrometeorological tower was set up in a southwest Amazon basin at the Biological Reserve of Jaru (Rebio Jaru: $10^{\circ} 04^{\prime} \mathrm{S}, 61^{\circ} 56^{\prime} \mathrm{W}$ ) in Rondônia State of Brazil; with instruments located at two different heights: abovecanopy at $66 \mathrm{~m}$ and inside-canopy at $21 \mathrm{~m}$, to make simultaneous measurements of eddy covariance and vertical profiles of air temperature, wind velocity, radiation and humidity. Three-dimensional wind velocity and air temperature measurements were made at a sampling rate of $60 \mathrm{~Hz}$, using sonic anemometers and thermometers.

In this paper we investigate the atmospheric turbulence data taken from noon to 12:30 on Julian Day 068, when the forest crown is heated by the solar radiation. A dataset of 108000 points for temperature and vertical velocity is used for this analysis. During this period the top of the canopy is hotter than its surroundings, thus temperatures decrease both upwards towards the atmosphere above the canopy and downwards towards the ground surface, resulting in an unstably stratified atmosphere above the canopy and a stably stratification region inside the canopy. Figure 1 shows the original time series of temperature $T$ and vertical wind velocity $w$ above and within the Amazon forest canopy. 


\section{ABOVE-CANOPY}
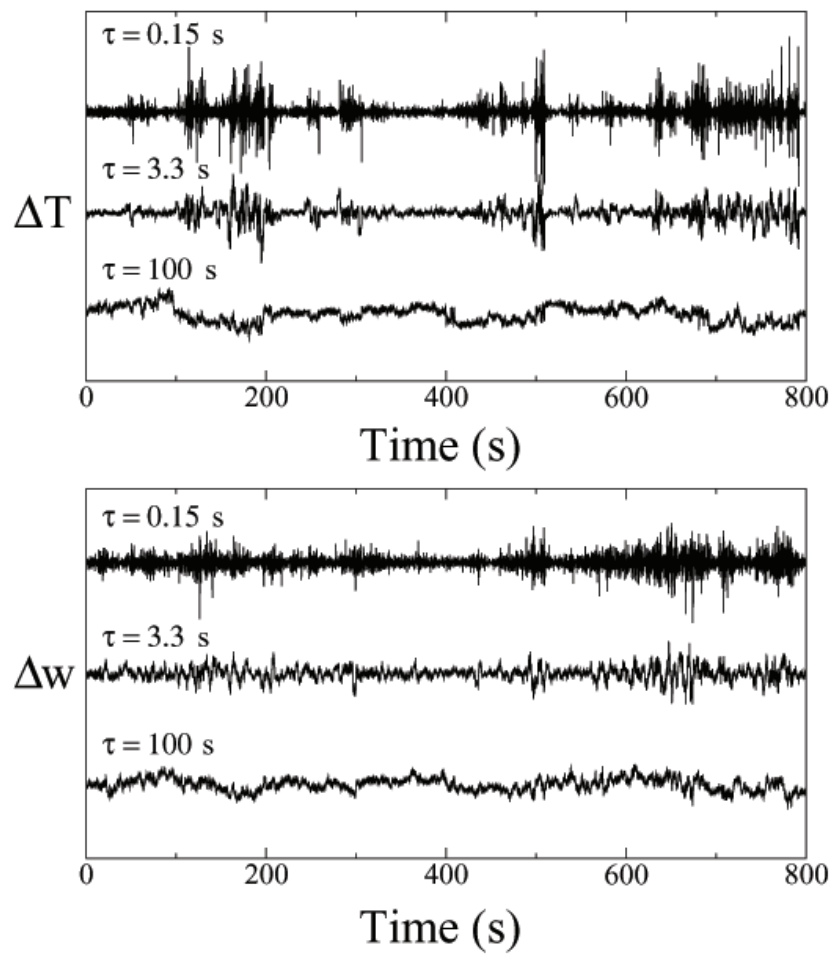

Fig. 2. Scale dependence of the normalized temperature-difference $\Delta T$ and the normalized vertical wind velocity-difference $\Delta w$ above the Amazon forest canopy for three different time scales $(\tau=0.15 \mathrm{~s}$, $3.3 \mathrm{~s}$ and $100 \mathrm{~s})$.

\section{Intermittency and phase coherence in atmospheric turbulence}

Figures 2 and 3 show, respectively, the scale dependence of the normalized temperature-difference $\Delta T=(\delta T-<\delta T>) / \sigma_{T}$ and the normalized vertical wind velocity-difference $\Delta w=(\delta w-<\delta w>) / \sigma_{w}$ above and within the Amazon forest canopy, respectively, for three different time scales $(\tau=0.15 \mathrm{~s}, 3.3 \mathrm{~s}$ and $100.0 \mathrm{~s})$, where $\delta u=u(t+\tau)-u(t)$ denotes the two-point difference of vertical wind velocity $w$ or temperature $T$ for a given time scale $\tau$, the brackets denote the mean value of $\delta u$, and $\sigma_{u}$ denotes the standard deviation of $\delta u$. Evidently, the fluctuations in Figs. 2 and 3 become more intermittent as the scale becomes smaller.

The intermittent characteristics of Amazon atmospheric turbulence can be elucidated by the probability density function (PDF) of the temperature and vertical wind velocity fluctuations. Figure 4 shows the PDF of the normalized temperature-difference $\Delta T$ (right panels) and the normalized vertical wind velocity-difference $\Delta w$ (left panels) fluctuations above the Amazon forest canopy for 3 different scales $(\tau=0.15 \mathrm{~s}, 3.3 \mathrm{~s}$ and $100.0 \mathrm{~s}$, indicated by a, b and c, respectively, in Fig. 7), superposed by a Gaussian PDF (gray line).

\section{IN-CANOPY}
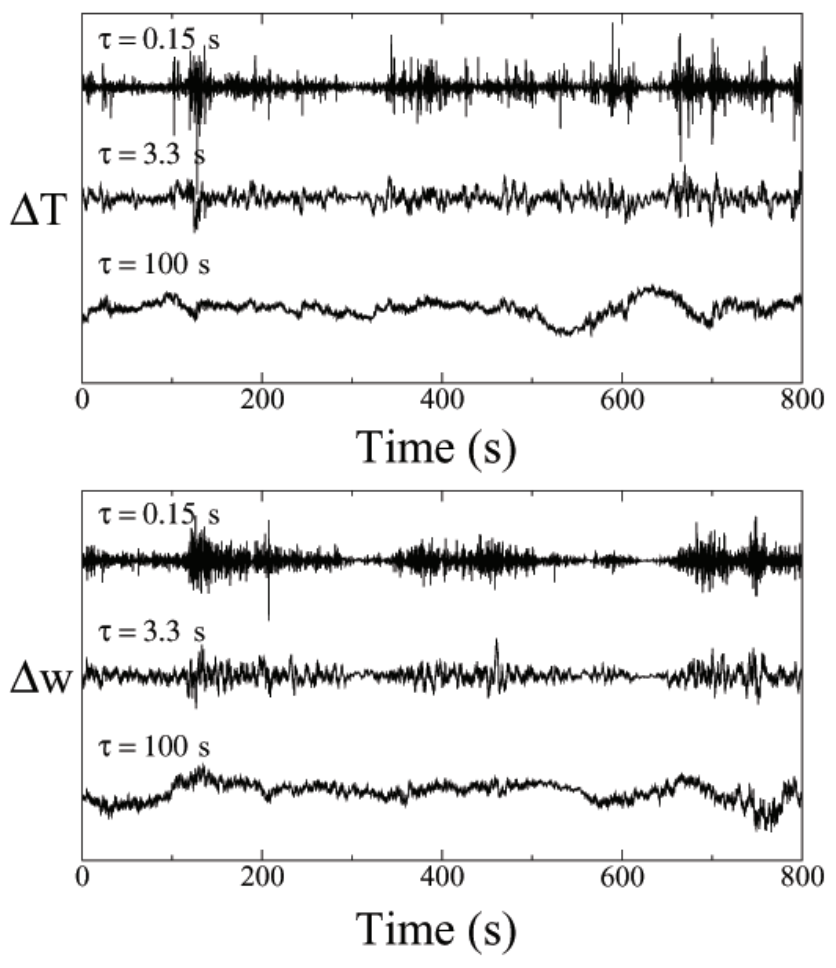

Fig. 3. Scale dependence of the normalized temperature-difference $\Delta T$ and the normalized vertical wind velocity-difference $\Delta w$ within the Amazon forest canopy for three different time scales ( $\tau=0.15 \mathrm{~s}, 3.3 \mathrm{~s}$ and $100 \mathrm{~s}$ ).

Figure 5 shows the corresponding PDFs inside the Amazon forest canopy. It follows, from Figs. 4 and 5, that for both temperature and vertical wind velocity the PDF is close to the Gaussian distribution at large scale $(\tau=100 \mathrm{~s})$ but deviates substantially from the Gaussian distribution as the scale $\tau$ decreases. At small scales ( $\tau=0.15 \mathrm{~s}$ and $3.3 \mathrm{~s}$ ) the shape of PDF becomes leptokurtic, exhibiting fat tails and sharp peaks. Figures 4 and 5 show that the tails of PDF get longer and the peaks of PDF get sharper as the scale decreases.

Intermittency can be quantified by calculating the variation of the normalized fourth-order structure function $K$ (kurtosis) with scale $\tau$, $K(\tau)=(1 / n) \sum_{i=1}^{n}\left(\left(\delta u_{i}-<\delta u_{i}>\right) / \sigma_{u}\right)^{4}-3$. For an intermittent signal $K(\tau)>0$ and $K$ increases when scale decreases; for a Gaussian noise $K=0$ for all scales. Top panels of Figs. 6 and 7 show the computed variation of $K$ with scale $\tau$ for temperature and vertical wind velocity, above and inside the Amazon forest canopy, where the horizontal bar denotes the inertial subrange, approximately from $0.15 \mathrm{~s}$ to $3.3 \mathrm{~s}$ (Bolzan et al., 2002; Ramos et al., 2004), estimated by the method of Kulkarni et al. (1999) using isotropy coefficient calculated by the Haar wavelet transform. 


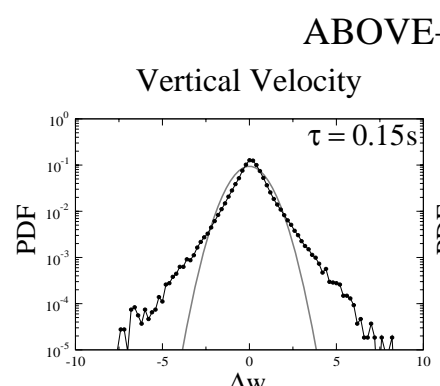

ABOVE-CANOPY
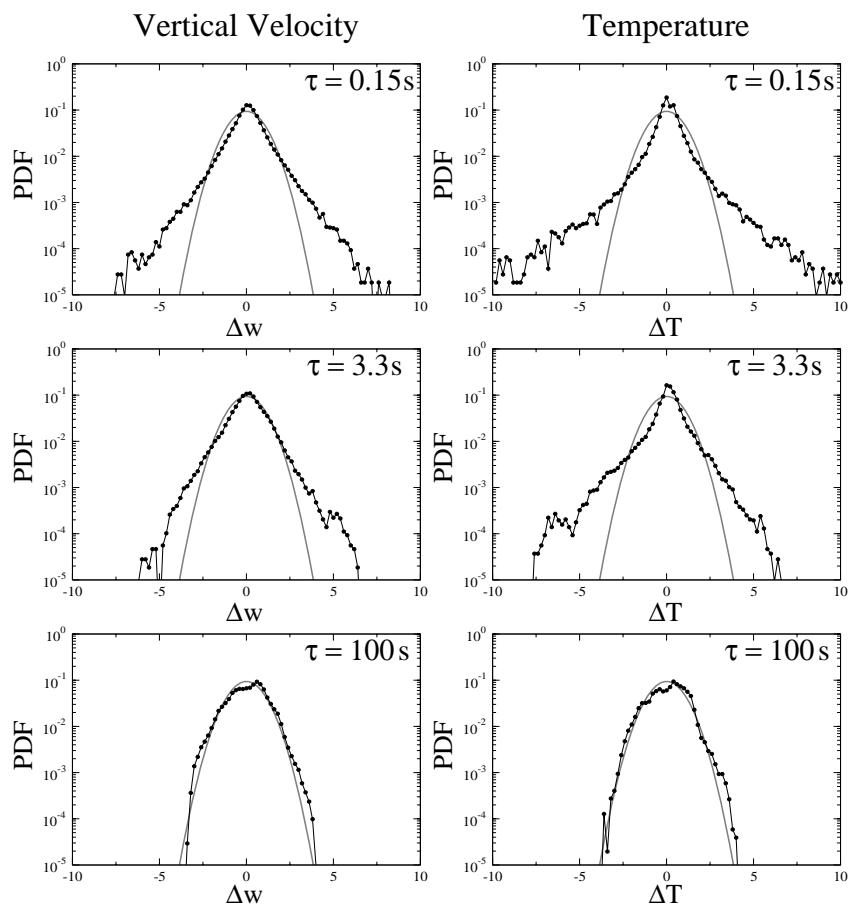

Fig. 4. Probability density distribution (PDF) of the normalized vertical wind velocity-difference $\Delta w$ (left panels) and the normalized temperature-difference $\Delta T$ (right panels) fluctuations above the Amazon forest canopy for three different scales $(\tau=0.15 \mathrm{~s}, 3.3 \mathrm{~s}$ and $100.0 \mathrm{~s}$ ), superposed by a Gaussian PDF (gray line).

An alternative way of quantifying intermittency is to apply the phase coherence technique using surrogate data by defining a phase coherence index (Hada et al., 2003; Koga et al., 2007, 2008), $C_{\phi}(\tau)=\left(S_{\mathrm{PRS}}(\tau)-S_{\mathrm{ORG}}(\tau)\right) /\left(S_{\mathrm{PRS}}(\tau)-\right.$ $\left.S_{\mathrm{PCS}}(\tau)\right)$. This index measures the degree of phase coherence in an original data set (ORG) by comparing it with two surrogate data sets created from the original data set: the phase-randomized surrogate (PRS) in which the phases of the Fourier modes are made completely random, and the phase-correlated surrogate (PCS) in which the phases of the Fourier modes are made completely equal. The power spectrum of three data sets ORG, PRS and PCS are kept the same, but their phase distributions are different. Each length of ORG, PRS and PCS data set is measured by the magnitude of first-order structure function $S_{1}(\tau)=\sum_{i=1}^{n}\left|u_{i+\tau}-u_{i}\right|$. An average of over 100 realizations of the phase shuffling is performed to generate the phase-randomized surrogate data set $S_{\text {PRS }}(\tau) . C_{\phi}(\tau)=0$ indicates that the phases of the scales $\tau$ of the original data are completely random, whereas $C_{\phi}(\tau)=1$ indicates that the phases are completely correlated. Bottom panels of Figs. 6 and 7 show the computed variation of $C_{\phi}$ with scale $\tau$ for temperature and vertical wind velocity above and inside the Amazon forest canopy.

Figure 6 confirms that both kurtosis and phase coherence index can be used to measure the degree of intermittency

\section{IN-CANOPY}
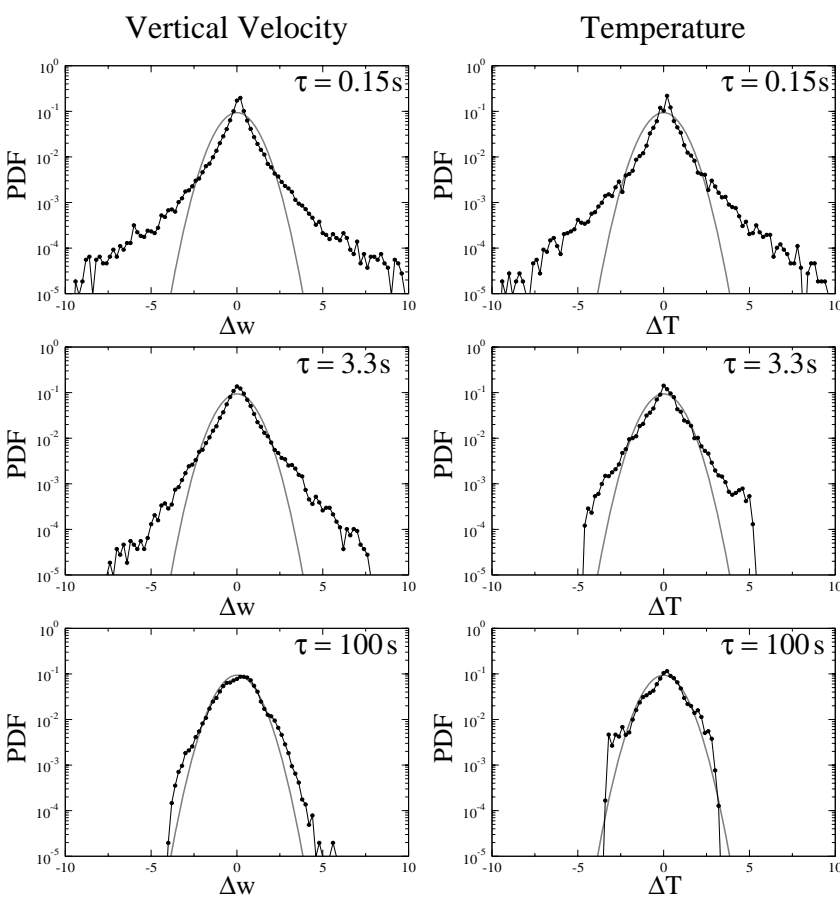

Fig. 5. Probability density distribution (PDF) of the normalized vertical wind velocity-difference $\Delta w$ (left panels) and the normalized temperature-difference $\Delta T$ (right panels) fluctuations within the Amazon forest canopy for three different time scales $(\tau=0.15 \mathrm{~s}$, $3.3 \mathrm{~s}$ and $100.0 \mathrm{~s}$ ), superposed by a Gaussian PDF (gray line).

and phase coherence in turbulence. Left panels of Fig. 6 show that for all scales $\tau \lesssim 35$ s the in-canopy vertical velocity is more intermittent than the above-canopy vertical velocity. Right panels of Fig. 6 show that for small scales outside the inertial subrange the in-canopy temperature is more intermittent than the above-canopy temperature; whereas, for scales within and greater than the inertial subrange the in-canopy temperature is less intermittent than the above-canopy temperature.

\section{Scalar-velocity dissimilarity in atmospheric intermit- tent turbulence}

The dissimilarity between temperature (scalar) and vertical wind velocity (momentum) can be elucidated by Figs. 4, 5 and 7. Figure 4 shows that for scales $\tau=0.15 \mathrm{~s}$ and $3.3 \mathrm{~s}$ (a and $b$ in Fig. 7) the PDFs of temperature fluctuations have longer tails and sharper peaks than the PDFs of vertical velocity fluctuations, implying that at these scales temperature is more intermittent than vertical wind velocity above the Amazon forest canopy. The scalar-velocity dissimilarity above the canopy is clearly characterized by both kurtosis and phase coherence techniques in the left panels of Fig. 7, 

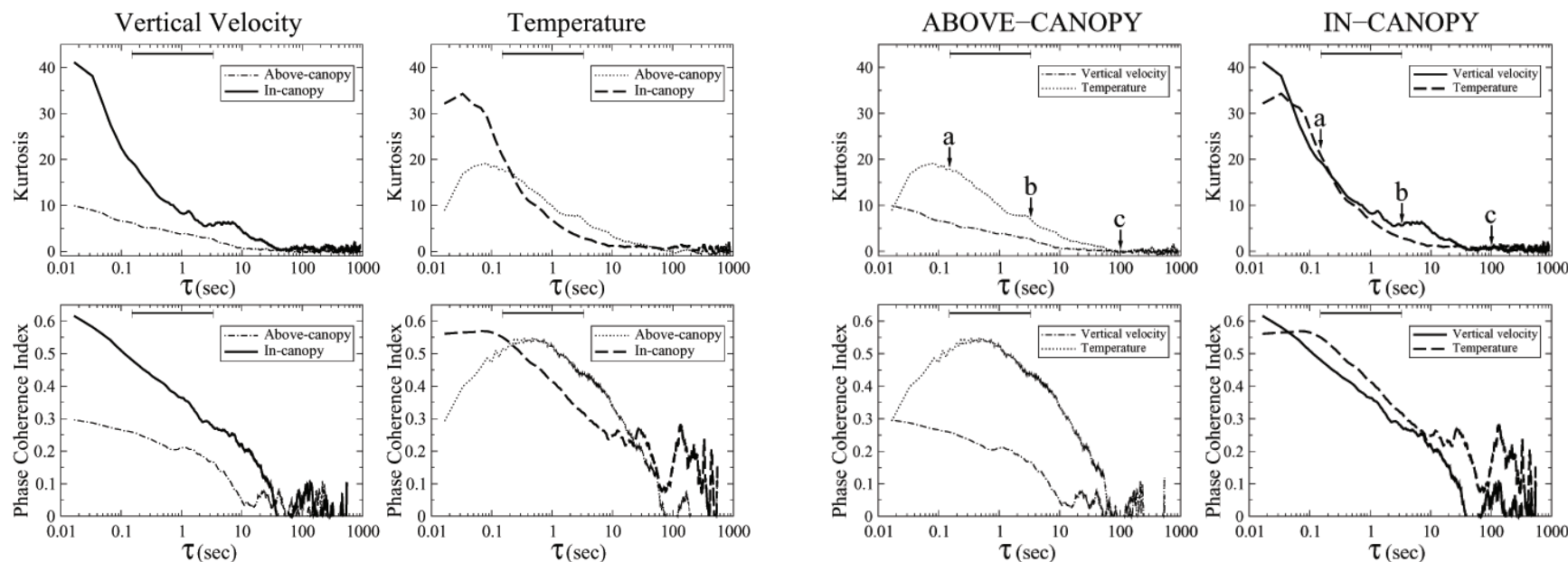

Fig. 6. Kurtosis and Phase Coherence Index of vertical wind velocities (left panels) and temperatures (right panels) above and within the Amazon forest canopy. Thick solid lines denote the in-canopy vertical wind velocity, thin dash-dotted lines denote the abovecanopy vertical wind velocity, thick dashed lines denote the incanopy temperature, and thin dotted lines denote the above-canopy temperature. The bar indicates the inertial subrange (approximately from $\tau=0.15 \mathrm{~s}$ to $3.3 \mathrm{~s}$ ).

which show that the above-canopy temperature is more inter-

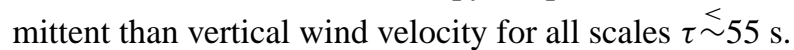

In contrast, the right panels of Fig. 7 show that the scalarvelocity dissimilarity of the in-canopy turbulence is greatly reduced. The scalar-velocity similarity inside the canopy is evidenced in Fig. 5 which shows that, at $\tau=0.15 \mathrm{~s}$ the PDFs of temperature and vertical wind velocity have similar sharp peaks and long-tail statistics.

\section{Conclusions}

In this paper, we applied two different nonlinear techniques, kurtosis and phase coherence index, to analyze day-time atmospheric data above and within an Amazon forest canopy. We showed that the scale dependence of kurtosis and phase coherence index for vertical wind velocity and temperature above and within canopy exhibit similar behaviors, as seen in Fig. 6. In particular, both techniques demonstrate a clear enhancement of scalar-velocity similarity for in-canopy turbulence in comparison to its above-canopy counterpart, as seen in Fig. 7. Our results prove that the atmospheric intermittent turbulence, above and within the Amazon forest canopy, is generated by the phase coherence due to nonlinear wave-wave interactions. Turbulence consists of an admixture of chaos and noise. Recent studies have identified the chaotic nature of the solar-terrestrial environment (Macek, 1998; Chian et al., 2006) and the atmospheric turbulence above the Amazon forest (Campanharo et al., 2008), which have been confirmed by computer simulations of temporal
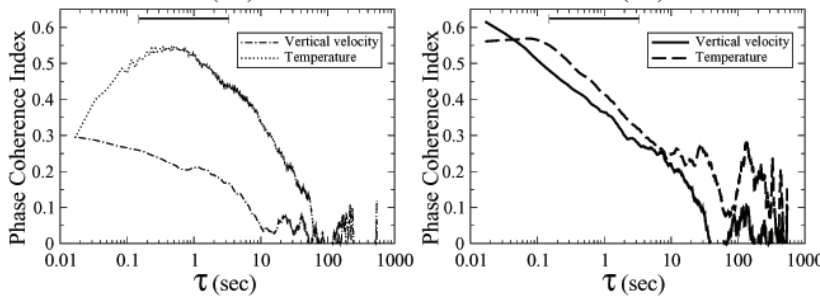

Fig. 7. Kurtosis and Phase Coherence Index of vertical wind velocities and temperatures above (left panels) and within (right panels) the Amazon forest canopy. Thick solid lines denote the in-canopy vertical wind velocity, thin dash-dotted lines denote the abovecanopy vertical wind velocity, thick dashed lines denote the incanopy temperature, and thin dotted lines denote the above-canopy temperature. Letters $\mathrm{a}, \mathrm{b}$ and $\mathrm{c}$ indicate scales $\tau=0.15 \mathrm{~s}, 3.3 \mathrm{~s}$ and $100.0 \mathrm{~s}$, respectively. The bar indicates the inertial subrange (approximately from $\tau=0.15 \mathrm{~s}$ to $3.3 \mathrm{~s}$ ).

chaos and spatiotemporal chaos in fluids and plasmas (Chian et al., 2006; Rempel and Chian, 2007; Rempel et al., 2007). It is likely that phase coherence and chaotic synchronization are the origin of energy bursts and coherent structures of turbulence in the complex earth-ocean-space system (He and Chian, 2003, 2005).

The turbulent exchange of mass and momentum from and within canopies is dominated by coherent structures (Finnigan, 2000). Wesson et al. (2003) applied three nonlinear time series techniques (Shannon entropy, wavelet thresholding, and mutual information content) to contrast the level of organization in vertical wind velocity in the canopy sublayer and the atmospheric surface layer. In the present paper, we have demonstrated that both kurtosis and phase coherence index techniques are capable of characterizing the degree of departure from Gaussianity, due to phase coherence, of atmospheric intermittent turbulence. The nonlinear techniques discussed in this paper can be applied to investigate the role played by coherent structures in experimental (Gao et al., 1989; Barthlott et al., 2007), theoretical (Raupach, 1996; Harman and Finnigan, 2007), and large-eddy simulation (Su et al., 1998; Qiu et al., 2008) studies of atmospheric turbulence in forest canopy, as well as in orchard canopy (Wang et al., 1992; Stoughton et al., 2002), rice canopy (Gao et al., 2003), corn canopy (Yue et al., 2007; Zhu et al., 2007), cotton and grape canopies (Mitic et al., 1999), coral canopy (Reidenbach et al., 2007), and urban canopy (Feigenwinter and Vogt, 2005; Salmond et al., 2005). 
Acknowledgements. This research is supported by CAPES, CNPq and FAPESP.

Edited by: K. Stasiewicz

Reviewed by: one anonymous referee

\section{References}

Barthlott, C., Drobinski, P., Fesquet, C., Dubos, T., and Pietras, C.: Long-term study of coherent structures in the atmospheric surface layer, Bound.-Lay. meteorol., 125, 1-24, 2007.

Bolzan, M. J., Ramos, F. M., Sá, L. D. A., Rodrigues Neto, C., and Rosa, R. R.: Analysis of fine-scale canopy turbulence within and above an Amazon forest using Tsallis' generalized thermostatistics, J. Geophys. Res.-Atmos., 107(D20), 8063, doi:10.1029/2001JD000378, 2002.

Campanharo, A. S. L. O., Ramos, F. M., Macau, E. E. N., Rosa, R. R., Bolzan, M. J. A., and Sá, L. D. A.: Searching chaos and coherent structures in the atmospheric turbulence above the Amazon forest, Phil. Trans. Royal Soc. London - math. and Phys. Sci., 366, 579-589, 2008.

Chian, A. C.-L., Kamide, Y., Rempel, E. L., and Santana, W M.: On the chaotic nature of solar-terrestrial environment: interplanetary Alfvén intermittency, J. Geophys. Res.-Space Phys., 111, A07S03, doi:10.1029/2005JA011396, 2006.

Feigenwinter, C. and Vogt, R.: Detection and analysis of coherent structures in urban turbulence, Theor. Appl. Climatol., 81, 219230, 2005.

Finnigan, J.: Turbulence in plant canopies, Ann. Rev. Fluid mech., 32, 519-571, 2000.

Fitzjarrald, D. R., Moore, K. E., Cabral, O M. R., Scolar, J., Manzi, A. O., and Sá, L. D. A.: Daytime turbulent exchange between the Amazon forest and the atmosphere, J. Geophys. Res.-Atmos., 95(D10), 16 825-16838, 1990.

Frisch, U.: Turbulence - The Legacy of A. N. Kolmogorov, Cambridge Univ. Press, Cambridge, 1995.

Gao, W., Shaw, R. H., and Paw, K. T.: Observation of organized structure in turbulent-flow within and above a forest canopy, Bound.-Lay. meteorol., 47, 349-377, 1989.

Gao, Z., Bian, L., and Zhou, X.: Measurements of turbulent transfer in the near-surface layer over a rice paddy in China, J. Geophys. Res.-Atmos., 108(D13), 4387, doi:10.1029/2002JD002779, 2003.

Hada, T., Koga, D., and Yamamoto, E.: Phase coherence of MHD waves in the solar wind, Space Sci. Rev., 107, 463-466, 2003.

Harman, I. N. and Finnigan, J. J.: A simple unified theory for flow in the canopy and roughness sublayer, Bound.-Lay. meteorol., 123, 339-363, 2007.

He, K. F. and Chian, A. C.-L.: On-off collective imperfect phase synchronization and bursts in wave energy in a turbulent state, Phys. Rev. Lett., 91, 034102, 2003.

He, K. F. and Chian, A. C.-L.: Nonlinear dynamics of turbulent waves in fluids and plasmas. Nonlinear Proc. Geophys., 12, 1324, 2005.

Katul, G., Poporato, A., Cava, D., and Siqueira, M.: An analysis of intermittency, scaling, and surface renewal in atmospheric surface layer turbulence, Physica D, 215, 117-126, 2006.

Koga, D., Chian, A. C.-L., Hada, T., and Rempel, E. L.: Experimental evidence of phase coherence of magnetohydrodynamic turbu- lence in the solar wind: GEOTAIL satellite data, Phil. Trans. Royal Soc. London - Math. and Phys. Sci., 366, 447-457, 2008.

Koga, D., Chian, A. C.-L., Miranda, R. A., and Rempel, E. L.: Intermittent nature of solar wind turbulence near the Earth's bow shock: Phase coherence and non-Gaussianity, Phys. Rev. E, 75, 046401, 2007.

Kulkarni, J. R., Sadani, L. K., and Murthy, B. S.: Wavelet analysis of intermittent turbulent transport in the atmospheric surface layer over a monsoon trough region, Bound.-Lay. meteorol., 90, 217-239, 1999.

Macek, W. M.: Testing for an attractor in the solar wind flow, Physica D, 122, 254-264, 1998.

Mitic, C. M., Massman, W. J., Schuepp, P. H., and Collett Jr., J. L.: Structural analysis and flux associations of $\mathrm{CO}_{2}, \mathrm{H}_{2} \mathrm{O}$, heat and ozone over cotton and grape canopies, Atmos. Environ., 33, 1159-1173, 1999.

Nariyuki, Y. and Hada, T.: Remarks on nonlinear relation among phases and frequencies in modulational instabilities of parallel propagating Alfvén waves, Nonlinear Proc. Geophys., 13, 425441, 2006.

Qiu, J., Gu, Z. L., and Wang, Z. S.: Numerical study of the response of an atmospheric surface layer to a spatially nonuniform plant canopy, Bound.-Lay. meteorol., 127, 293-311, 2008.

Ramos, F M., Bolzan, M. J. A., Sá, L. D. A., and Rosa, R. R.: Atmospheric turbulence within and above an Amazon forest, Physica D, 193, 278-291, 2004.

Raupach, M. R., Finnigan, J. J., and Brunet, Y.: Coherent eddies and turbulence in vegetation canopies: The mixing-layer analogy, Bound.-Lay. Meteorol., 78, 351-382, 1996.

Reidenbach, M. A., Koseff, J. R., and Monismith, S. G.: Laboratory experiments of fine-scale mixing and mass transport within a coral canopy, Phys. Fluids, 19, 075107, 2007.

Rempel, E. L. and Chian, A. C.-L.: Origin of transient and intermittent dynamics in spatiotemporal chaotic systems, Phys. Rev. Lett., 98, 014101, 2007.

Rempel, E. L., Chian, A. C.-L., and Miranda, R. A.: Chaotic saddles at the onset of intermittent spatiotemporal chaos, Phys. Rev. E, 76, 056217, 2007.

Salmond, J. A., Oke, T. R., Grimmond, C. S. B., Roberts, S., and Offerle, B.: Venting of heat and carbon dioxide from urban canyons at night, J. Appl Meteorol., 44, 1180-1194, 2005.

Silva Dias, M. A. F., Rutledge, S., Kabat, P., Silva Dias, P. L., Nobre, C., Fisch, G., Dolman, A. J., Zipser, E., Garstang, M., Manzi, A. O., Fuentes, J. D., Rocha, H. R., Marengo, J., Plana-Fattori, A., Sá, L. D. A., Alvalá, R. C. S., Andreae, M. O., Artaxo, P., Gielow, R., and Gatti, L.: Cloud and rain processes in a biosphere-atmosphere interaction context in the Amazon region, J. Geophys. Res.-Atmos., 107(D20), 8072, doi:10.1029/2001JD000335, 2002.

Simon, E., Lehmann, B. E., Ammann, C., Ganzeveld, L., Rummel, U., Meixner, F. X., Nobre, A. D., Araújo, A., and Kesselmeier, J.: Lagrangian dispersion of ${ }^{222} \mathrm{Rn}, \mathrm{H}_{2} \mathrm{O}$ and $\mathrm{CO}_{2}$ within Amazonian rain forest, Agricultural and Forest meteorol., 132, 286-304, 2005.

Sternberg, L. D. L., Moreira, M. Z., Martinelli, L. A., Victoria, R. L., Barbosa, E M., Bonates, L. C M., and Nepstad, D. C.: Carbon dioxide recycling in two Amazonian tropical forests, Agricultural and Forest meteorol., 88, 259-268, 1997.

Stoughton, T. E., Miller, D. R., Huddleston, E. W., and Ross, J. B.: 
Evapotranspiration and turbulent transport in an irrigated desert orchard, J. Geophys. Res.-Atmos., 107, 4425, 2002.

Su, H.-B., Shaw, R. H., Paw U, K. T., Moeng, C.-H., and Sullivan, P. P.: Turbulent statistics of neutrally stratified flow within and above a sparse forest from large-eddy simulation and field observations, Bound.-Lay. meteorol., 88, 363-397, 1998.

Thomas, C., Mayer, J.-C., Meixner, F. X., and Foken, T.: Analysis of low-frequency turbulence above tall vegetation using a Doppler Sodar, Bound.-Lay. meteorol., 119, 563-587, 2006.

Wang, Y. S., Miller, D. R., Anderson, D. E., Cionco, R M., and Lin, J. D.: A spatial length scale analysis of turbulent temperature and velocity fluctuations within and above an orchard canopy, Bound.-Lay. meteorol., 59, 125-139, 1992.
Wesson, K. H., Katul, G. G. and Siqueira, M.: Quantifying organization of atmospheric turbulent eddy motion using nonlinear time series analysis, Bound.-Lay. meteorol., 106, 507-525, 2003.

Yue, W., Parlange, M. B., Meneveau, C., Zhu, W., van Hout, R. and Katz, J.: Large-eddy simulation of plant canopy flows using plant-scale representation. Bound.-Lay. meteorol., 124, 183-203, 2007.

Zhu, W., van Hout, R., and Katz, J.: PIV measurements in the atmospheric boundary layer within and above a mature corn canopy. Part II: Quadrant-hole analysis, J. Atmospheric Sci., 64, 28252838, 2007. 